\title{
Diagnostic anterior chamber paracentesis in uveitis: a safe procedure?
}

\author{
Allegonda Van der Lelij, Aniki Rothova
}

\begin{abstract}
Background-Differentiation between infectious and non-infectious uveitis is of crucial value for accurate management of patients with uveitis. Tests performed on aqueous humour yield more relevant information than those done in serum. The objective of this study was to evaluate whether the aqueous humour tap for diagnostic purposes is a safe procedure to perform in uveitis patients.

Methods-In this retrospective study 361 patients with uveitis, who underwent a diagnostic anterior chamber paracentesis in an outpatient clinic, were investigated. 72 of the 361 patients were examined 30 minutes after the puncture. The site of the paracentesis, the depth of the anterior chamber, and cells in the anterior chamber were examined. All 361 patients were evaluated within 2 weeks after the paracentesis was performed. The final follow up period varied from 6 months to more than 3 years. The clinical data were analysed with the emphasis on the occurrence of cataract and a history of corneal infections or endophthalmitis.
\end{abstract}

Results-In this series no serious side effects such as cataract, keratitis, or endophthalmitis were observed. The depth of the anterior chamber of all evaluated patients was restored after 30 minutes. In five out of 72 cases (three AIDS patients with cytomegalovirus retinitis and two patients with anterior uveitis due to herpes simplex virus) a small hyphaema was observed 30 minutes after the paracentesis took place.

Conclusion-Anterior chamber paracentesis appears to be a safe procedure in the hands of an experienced ophthalmologist. (Br f Ophthalmol 1997;81:976-979)

Department of Ophthalmology, F C Donders Institute, University Hospital Utrecht, Utrecht, Netherlands

A Van der Lelij

A Rothova

Correspondence to: A Van der Lelij, MD, PhD, Department of

Ophthalmology, University

Hospital Utrecht, PO Box

85500, 3508 GA Utrecht,

Netherlands.

Accepted for publication 10 June 1997 since in these patients more than one causative agent could be involved. ${ }^{34}$ Patients with posterior intraocular inflammation from different aetiologies may share similar clinical characteristics. In that case the effectiveness of the instituted therapy often serves as a confirmation of the diagnosis. However, the exact aetiology frequently remains unknown, especially when micro-organisms are involved and all respond well to the same drug therapy. Besides this, during active inflammation the visualisation of the retina may be hampered by the vitreous opacities which prevent an accurate diagnosis.

Since intraocular inflammation caused by viruses can be progressive and devastating, ${ }^{5-7}$ the timely and precise diagnosis and specific antimicrobial therapy may be sight saving. ${ }^{8}$ The aqueous humour analysis contributes to this goal. Intraocular detection of antibodies to certain micro-organisms or DNA of viruses, bacteria, or parasites by means of the polymerase chain reaction (PCR) improves early and specific diagnosis. ${ }^{9} 10$

Anterior chamber paracentesis for diagnostic purposes is not yet a routinely used technique. In Europe it has gained in importance during the past two decades. ${ }^{10-13}$ In the USA, however, retinal or choroidal biopsies in sight threatening uveitis are usually performed without previous analysis of the aqueous humour obtained by means of an anterior chamber tap. ${ }^{14}$

This retrospective study was undertaken to determine the safety of diagnostic anterior chamber paracentesis in patients with uveitis.

\section{Patients and methods}

From 1993 to the end of 1996 the aqueous humour of 361 patients with uveitis of unknown origin was collected for diagnostic purposes. All patients (except for the immunocompromised patients) who underwent anterior chamber paracentesis, were previously screened following an instituted uveitis protocol (standardised laboratory investigation of serum, chest radiography, and eventually Mantoux skin test ${ }^{1}$ ), and the results of these tests were within the normal limits. All 361 individuals were suspected of having infectious uveitis on clinical grounds (Fuchs' heterochromic cyclitis and intermediate uveitis were excluded).

A standardised procedure was used for anterior chamber paracentesis in all patients. We used the microscope to perform the anterior chamber tap. Local anaesthesia was given by instilling $1 \%$ amethocaine (tetracaine) and $0.4 \%$ oxybuprocaine eyedrops three times with an interval of 10 minutes. Retrobulbar anaesthesia was not used. The patient was positioned in a surgical chair in a supine position. A 


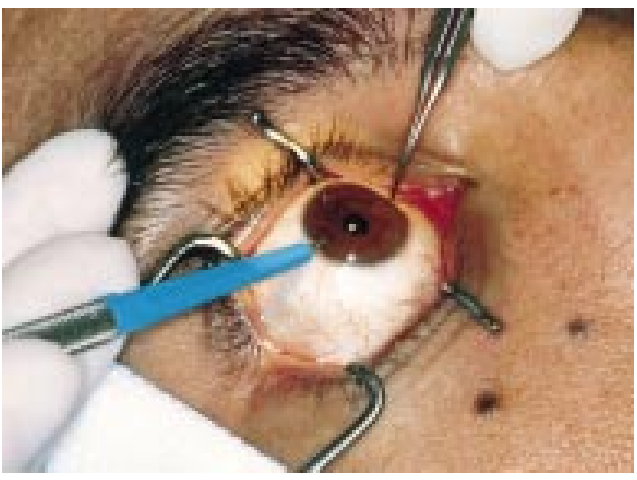

Figure 1 Preincision, made with a $15^{\circ}$ micro sharp blade.

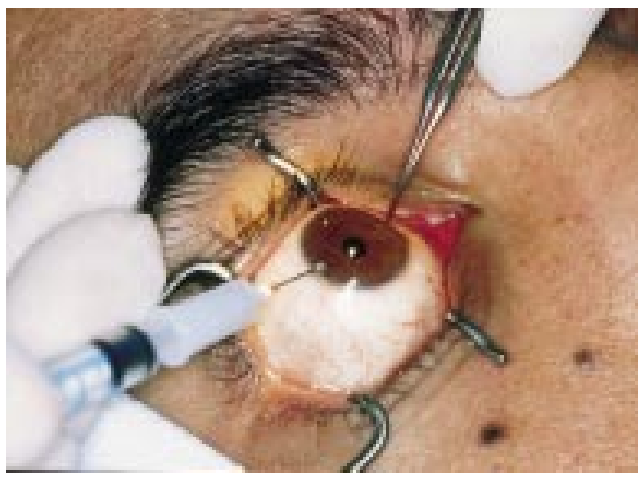

Figure 2 The aqueous humour tap, while fixating the eyeball with a forceps.

lid speculum was used to spread the eyelids. The eyeball was fixated firmly at the limbus by one hand, while a preincision was made with a $3 \mathrm{~mm}$ depth $15^{\circ}$ micro sharp blade (Beaver, Becton Dickinson AcuteCare, Franklin Lakes, NY, USA) using the other hand. This corneal preincision was parallel to the iris and the entry position next to the limbus. The incision just stopped after Descemet's membrane was penetrated without losing aqueous humour (Fig 1). A volume of 100-200 $\mu \mathrm{l}$ aqueous humour usually was obtained from the anterior chamber with a 27 gauge 1.2 inch needle on a tuberculin syringe (Plastipak, Becton Dickinson, Dublin, Ireland) (Fig 2). The plunger was pulled up by an assistant to aspirate the aqueous. After the sampling an antibiotic ointment was administered and the eye was patched for 12 hours. Blood samples were also taken, as the analysis of the intraocular fluid requires paired samples of blood and aqueous humour. The whole procedure took less than 10 minutes and no additional treatment was given.

We preferred to puncture the anterior chamber, when the pupil was not dilated, but often an aqueous humour tap was indicated just after the ophthalmic examination with dilatation of the pupil. Therefore, in our series more than $65 \%$ of anterior chamber paracentesis were carried out in patients with a dilated pupil. In these cases the bevel of the needle is directed to and kept above the retracted iris to prevent touching the anterior capsule of the lens. None of the patients had an intraocular pressure of more than $30 \mathrm{~mm} \mathrm{Hg}$ at the time of sampling. In cases of higher intraocular pressure the procedure was postponed for several hours.
One of the authors (AVdL) examined 72 patients 30 minutes after the puncture. The site of the paracentesis as well as the anterior chamber were inspected, the latter with emphasis on the depth of the anterior chamber and the occurrence of red blood cells. All 361 patients were seen at 7-14 days and the follow up period varied from 6 months to more than 3 years.

In this study we analysed the patients' data retrospectively and noted whether complications had occurred as a result of the anterior chamber paracentesis. Emphasis was laid on the occurrence of cataract and a history of corneal infections or endophthalmitis. Nuclear and cortical cataracts related to advanced age or cataracts (in most cases subcapsular posterior) secondary to corticosteroids or the inflammatory disease were excluded from the analysis.

\section{Results}

None of the 361 patients developed cataract as a result of touching the anterior capsule of the lens, corneal disorders, or endophthalmitis. Of the 72 patients who were examined 30 minutes after the puncture, three AIDS patients with cytomegalovirus retinitis and two patients with anterior uveitis due to herpes simplex virus had a small hyphaema. These haemorrhages did not have the characteristics of Amsler's sign in Fuchs' heterochromic cyclitis. This phenomenon shows haemorrhages from the chamber angle that form fine filaments and end up in a small hyphaema. ${ }^{15}$ Moreover, there were no patients with Fuchs' heterochromic cyclitis among the studied individuals. The anterior chamber recovered its depth in all 72 patients examined and in the majority of patients, a minimal stromal opacification in the cornea was noted at the paracentesis site.

\section{Discussion}

The evaluation of the safety of invasive diagnostic procedures assessing the frequency and severity of eventual complications is crucial for their acceptance. Our results indicate that anterior chamber paracentesis appears to be a safe diagnostic tool. Until now, no systematic reports addressing the side effects of anterior chamber paracentesis were available. One case of bacterial endophthalmitis was reported after an anterior chamber paracentesis, albeit for therapeutical reasons - to lower the intraocular pressure in a patient with a central retinal artery occlusion. ${ }^{16}$ Recently, a corneal abscess was described in a paracentesis tract. ${ }^{17}$ Another strong motive for the present study was provided by the publication of four cases of endophthalmitis after radial keratotomy, performed without corneal perforation. ${ }^{18}$

The incidence of endophthalmitis after anterior chamber paracentesis is probably lower than in cataract surgery, for example, since the frequency of postoperative endophthalmitis seemed proportional to the duration of 


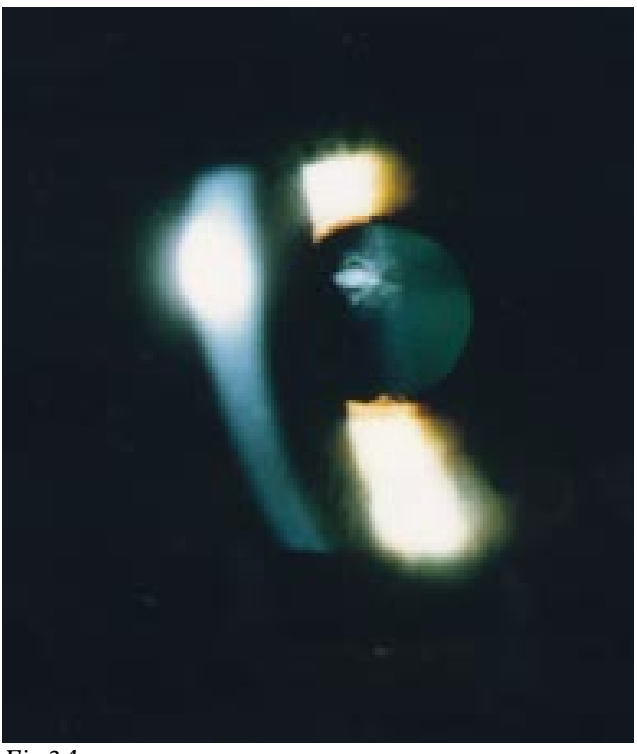

Fig $3 A$

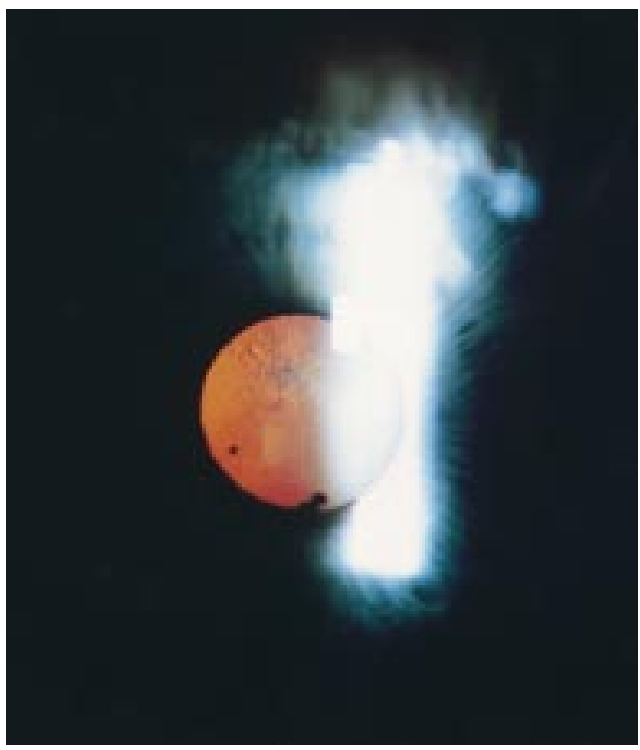

Fig $3 B$

Figure 3 Localised cataract in all probability caused by damaging the anterior capsule during the aqueous humour tap (for details see Discussion).

surgery. ${ }^{19}$ The incidence of postoperative endophthalmitis in cataract surgery is very low $(0.05-0.58 \%)$, depending on the type of surgery and integrity of the posterior capsule of the lens. ${ }^{20-22}$ The number of patients investigated in the present study is far less than the 338141 patients in the cataract study of Javitt et al. ${ }^{21}$ Thus, to determine the exact incidence of endophthalmitis in the anterior chamber paracentesis would require an extremely large number of patients, which is of course very difficult to realise. Although we did not use local antibiotic therapy before the procedure, we do now include instillation of $5 \%$ povidone-iodine solution to fill both the upper and lower fornices. It was proved that application of povidone-iodine decreased the number of colony forming bacteria in the conjunctival fornix, compared with a broad spectrum antibiotic. $^{23}$
Our technique for aqueous sampling includes the use of a microscope and requires the patient to be in a supine position. This gives an optimal visualisation of the anterior chamber during the procedure and minimises movement of patient's head. The latter, together with the corneal preincision, minimises the chance of touching the anterior capsule of the lens even with a dilated pupil. We are aware of the fact that it is common practice to puncture the anterior chamber just with a 27 or 30 gauge needle on a tuberculin syringe with the patient sitting behind the slit lamp. We had, however, the opportunity to examine a patient in whom the aqueous humour tap was performed with a 27 gauge needle using the slit lamp while the patient was in a upright position. She developed a localised cataract most probably due to the touch of the lens by the needle (Fig 3). This patient was referred to our department for a second opinion and did not participate in the present study. We consider our method with the preincision through the stroma and the Descemet's membrane safer, since the needle enters the anterior chamber smoothly and no force is required. The paracentesis can be performed in patients of about 18 years and older in an outpatient clinic, and no general or retrobulbar anaesthesia is required. For those ophthalmologists who have no experience in performing aqueous taps, we would recommend starting with pseudophakic eyes.

Our findings indicate that anterior chamber paracentesis is a relatively safe procedure and should precede the potentially more dangerous vitrectomy and retinal or choroidal biopsy. Recently, a special device for puncturing the anterior chamber, a so called aqueous pipette designed by O'Rourke $(0.30 \times 4 \mathrm{~mm}$ (30 gauge $\times 5 / 32$ inch) Visitec, Sarasota, FL, USA) has been put on the market. Whether this device is safe and superior to the present syringe technique remains to be investigated.

Although the indications for paracentesis are not yet exactly defined, the analysis of aqueous humour could be essential in cases with a questionable diagnosis, specifically in those cases with media opacities. The analysis of aqueous humour is also recommended for immunocompromised patients, because of the possibility of double and even triple viral infections. $^{34924}$ In the literature five immunocompromised patients have been reported, who had toxoplasma chorioretinitis which was misdiagnosed as cytomegalovirus retinopathy. ${ }^{25}$ In these patients the final diagnosis was based on a retinal biopsy or a rapid response to antiparasitic drug therapy. In such cases the results of aqueous analysis before a surgical procedure may be decisive to give the right choice of sight saving therapy.

In this study, anterior chamber paracentesis appeared to be a safe investigation procedure differentiating between infectious and noninfectious cause of uveitis. We recommend aqueous sampling only to experienced ophthalmologists, preferably to intraocular surgeons or specialists in uveitis, who will regularly perform this diagnostic procedure. 
1 Rothova A, Buitenhuis HJ, Meenken C, Brinkman CJJ, LinRothova A, Buitenhuis HJ, Meenken C, Brinkman CJJ, Lin-
ssen A, Alberts C, et al. Uveitis and systemic disease. Brf
Ophthalmol 1992;76:137-41.

2 Smit RLMJ, Baarsma GS, De Vries J. Classification of 750 consecutive uveitis patients in the Rotterdam Eye Hospital. Int Ophthalmol 1993;17:71-5.

3 Pepose JS, Hilborne LH, Cancilla PA, Foos RY. Concurrent herpes simplex and cytomegalovirus retinitis and encephalitis in the acquired immune deficiency syndrome (AIDS). Ophthalmology 1984;91:1669-77.

4 Rummelt V, Rummelt C, Jahn G, Wenekel H, Sinzger C, Mayer UM, et al. Triple retinal infection with human immunodeficiency virus type 1 , cytomegalovirus, and herpes simplex virus type 1. Ophthalmology 1994;101:270-9.

5 Forster DJ, Dugel PU, Frangieh GT, Liggett PE, Rao NA. Rapidly progressive outer retinal necrosis in the acquired immunodeficiency syndrome. Am f Ophthalmol 1990;110. 341-8.

6 Duker JS, Blumenkranz MS. Diagnosis and management of the acute retinal necrosis (ARN) syndrome. Surv Ophthalthe acute retinal necrosi
mol 1991;35:327-43.

7 Engstrom RE, Holland GN, Margolis TP, Muccioli C, Lindley JI, Belfort R, et al. The progressive outer retinal necrosis syndrome. A variant of necrotizing herpetic retinopathy in patients with AIDS. Ophthalmology 1994;101: 1488-502.

8 Teich SA, Cheng TO, Friedman AH. Systemic antiviral drugs used in ophthalmology. Surv Ophthalmol 1992;37: $19-53$.

9 Boer de JH, Verhagen C, Bruinenberg M, Rothova A, Jong de PTVM, Baarsma GS, et al. Serological and polymerase chain reaction analysis of intraocular fluids in the diagnosis of infectious uveitis. Am f Ophthalmol 1996;121:650-8.

10 Boer de JH, Luyendijk L, Rothova A, Kijlstra A. Analysis of ocular fluids for local antibody production in uveitis. $\mathrm{Br} \mathcal{F}$ Ophthalmol 1995;79:610-6.

11 Luyendijk L, Van den Horn GJ, Visser OHE, SuttorpSchulten MSA, Van der Biesen PR, Rothova A, et al. Detection of locally produced antibodies to herpesviruses in the aqueous of patients with acquired immune in the aqueous of patients with acquired immune deficiency syndrome (AIDS) or acute retinal

12 Baarsma GS, Luyendijk L, Kijlstra A, De Vries J, Peperkamp E, Mertens DAE, et al. Analysis of local antibody production in the vitreous humour of patient with severe uveitis. Am $\mathcal{F}$ Ophthalmol 1991;112:147-50.
13 Brézin AP, Eqwuagu CE, Silveira C, Thulliez $\mathrm{Ph}$, Martins MC, Mahdi RM, et al. Analysis of aqueous humor in ocular toxoplasmosis. $N$ Engl f Med 1991;324:699.

14 Rutzen AR, Ortega-Larrocea G, Dugel PU, Chong LP, Lopez PF, Smith RE, et al. Clinicopathologic study of retinal and choroidal biopsies in intraocular inflammation. $\mathrm{Am}$ 7 Ophthalmol 1995;119:597-611.

15 Amsler M, Verrey F. Hétérochromie de Fuchs et fragilité vasculaire. Ophthalmologica 1946;111:177-81.

16 Helbig H, Noske W, Kleineidam M, Kellner U, Foerster MH. Bacterial endophthalmitis after anterior chamber MH. Bacterial endophthalmitis after anter

17 Azuara-Blanco A, Katz LJ. Infectious keratitis in a paracentesis tract. Ophthalmic Surg Lasers 1997;28:332-3.

18 McLeod SD, Flowers CW, Lopez PF, Marx J, McDonnell PJ. Endophthalmitis and orbital cellulitis after radial keratotomy. Ophthalmology 1995;102:1902-7.

19 Speaker MG, Milch FA, Shah MK, Eisner W, Kreiswirth BN. Role of external bacterial flora in the pathogenesis of acute postoperative endophthalmitis. Ophthalmology 1991; 98:639-50.

20 Allen HF, Mangiaracine AB. Bacterial endophthalmitis after cataract extraction. II Incidence in 36,000 consecutive operations with special reference to preoperative topical antibiotics. Arch Ophthalmol 1974;91:3-7.

21 Javitt JC, Vitale S, Canner JK, Street DA, Krakauer H, McBean AM, et al. National outcome of cataract extraction. Endophthalmitis following inpatient surgery. Arch Ophthalmol 1991;109:1085-9.

22 Scott IU, Flynn HW, Feuer W. Endophthalmitis after secondary intraocular lens implantation. A case-control study. Ophthalmology 1995;102:1925-31.

23 Apt L, Isenberg SJ, Yoshimori R, Chang A, Lam GC, Wachler $\mathrm{B}$, et al. The effect of povidone-iodine solution applied at the conclusion of ophthalmic surgery. Am $\mathcal{f}$ Ophthalmol 1995;119:701-5.

24 Garweg J, Fenner T, Bohnke M, Schmitz H. An improved technique for the diagnosis of viral retinitis from samples of aqueous humour and vitreous. Graefes Arch Clin Exp Ophthalmol 1993;231:508-13.

25 Elkins BS, Holland GN, Opremcak EM, Dunn JP, Jabs DA, Johnston WH, et al. Ocular toxoplasmosis misdiagnosed as cytomegalovirus retinopathy in immunocompromised patients. Ophthalmology994;101:499-507. 